DOI: 10.18468/letras.2017v7n4.p223-244

\title{
Entre o desejo de escuta e os (des) velamentos da carne: a mulher entre a voz e o silencio em Dôra, Doralina, de
}

\section{Rachel de Queiroz}

\author{
Francisca Lailsa Ribeiro Pinto ${ }^{1}$ \\ Éderson Luís Silveira²
}

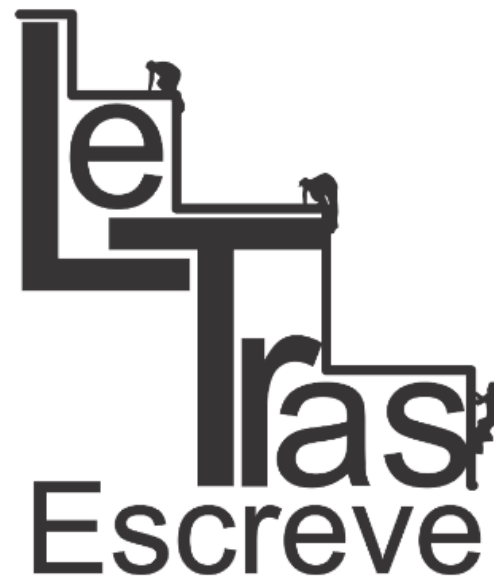

(ISSN 2238-8060)

Resumo: Esta pesquisa qualitativa de cunho documental e descritivo pautase na investigação de contribuições do ecofeminismo para os estudos literários a fim de possibilitar problematizações acerca de corpo, gênero e sexualidade. Dessa forma, a partir das contribuições do ecofeminismo lançaremos luzes sobre a primeira parte da obra ficcional Dôra, Doralina, de Rachel de Queiroz buscando refletir acerca do silêncio que se sustenta nas representações desiguais de gênero reproduzidas no imaginário cultural (re)produzido no interior das relações sociais da contemporaneidade. Conclui-se que a mulher, associada à natureza ou não, pode ser percebida a partir da identificação com ações de resistência ao domínio que incide sobre os gêneros e não apenas através do "papel" procriador, maternal, desejado, submisso, silenciado frente aos padrões que reforçam a manutenção de seu estado de dominação.

Palavras-chave: Literatura; Estudos de gênero; Corpo feminino.

Abstract: This qualitative research of documentary and descriptive nature guided in research contributions of ecofeminism for literary studies in order to enable reflections on body, gender, and sexuality. Thus, from the contributions of ecofeminism throw lights on the first part of the fictional book, Dora Doralina, Rachel de Queiroz seeking reflects about the silence that stands in the unequal gender representations reproduced on the cultural imaginary (re)produced within the social relations of contemporaneity. It is concluded that the woman, nature-related or not, can be perceived from the resistance actions identification field that focuses on the genres and not only through the paper, maternal parent, desired, Submissive, muted against the standards that reinforce the maintenance of their domination. Keywords: Literature; Gender studies; Female body.

\footnotetext{
${ }^{1}$ Mestre em Letras: estudos literários pela Universidade Federal da Paraíba - UFPB. E-mail: lailsalavigne@gmail.com

${ }^{2}$ Mestre e Doutorando em Linguística pela Universidade Federal de Santa Catarina - UFSC. E-mail: ediliteratus@gmail.com
}

https://periodicos.unifap.br/index.php/letras

Macapá, v. 7, n. 4, 20 semestre, 2017 


\section{Ingressando nos terrenos do olhar}

O ecofeminismo, apontando para as relações entre mulher e natureza, concilia duas lutas: a emancipação das mulheres e a luta pela preservação da natureza. (SALEH, 1992). De acordo com Saleh (1992), o surgimento deste movimento se dá na década de 70 quando mulheres vinculadas a movimentos feministas se voltam para questões ambientais devido à necessidade de considerar as relações dos corpos com o meio ambiente. Apesar de estabelecer-se a partir da percepção das ligações entre a emancipação das mulheres e a luta pela preservação da natureza, o movimento se dirige a todos os seres humanos para a busca da consciência global em relação às conse-

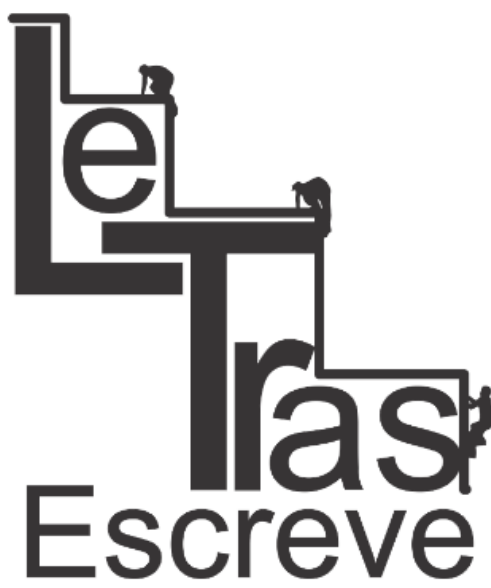

(ISSN 2238-8060) quências desastrosas da ação do homo sapiens sobre os recursos naturais para reverter o quadro de exploração e dominação tão assustadoramente acentuadas a cada ano sendo relatadas em relatórios internacionais de extinção de espécies entre outros.

Neste contexto, Ruether (1996) apresenta o ecofeminismo como sendo a união de dois elementos fundamentais de análise: a mulher e a natureza. Sob este ponto de vista a dominação das mulheres e da natureza encontram-se inter-relacionadas através da ação operada pelo patriarcado. Assim, esses dois tipos de dominação são exercidos a partir de interpretações "masculinistas" e é objetivo dos estudos ecofeministas produzir práticas e pensamentos que subvertam a ordem e o mito da separação entre mente e corpo, pensamento e sentimento e entre o dominante e os elementos subordinados.

Desse modo, o ecofeminismo busca operar situando-se no escopo de questões ambientais, visando a construção de um meio ambiente sustentável (GARCIA, 2012). Dessa forma, o adjetivo "sustentável" apresenta-se a partir da problematização contínua dos funda- 


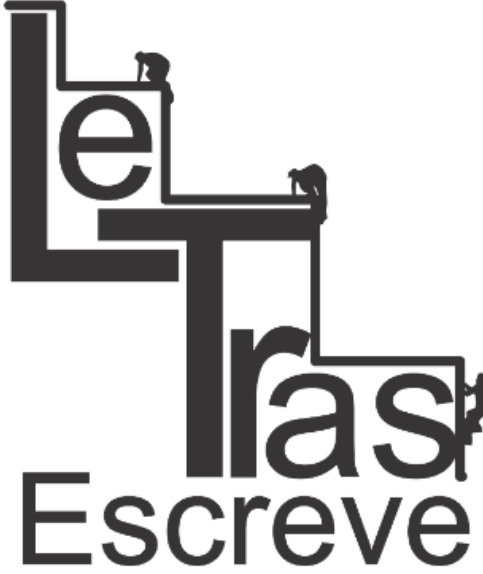

(ISSN 2238-8060) mentos que produzem efeitos nocivos na vida (ecologia) que precisa encontrar equilíbrio ao invés de hierarquizações opressoras. O presente trabalho parte de discussões que emergem a partir dos estudos ecofeministas para lançar luzes à obra ficcional Dôra, Doralina de Raquel de Queiroz.

Na obra mencionada, especificamente na primeira parte do romance, intitulada $O$ Livro de Senhora, texto de nossa análise, podem ser levantadas para reflexões acerca da relação entre gêneros mediados a partir das instâncias de dominação masculina, através de regimes patriarcais de poder sobre a mulher vista como frágil, cujo papel se resume na função de dona-de-casa, submissa, elementos representativos do imaginário sobre a personagem Senhora, mãe da protagonista. O "macho dominante", Laurinho (esposo de Dôra), neste contexto, é evidenciado através de referências como o fato de ser o "homem da casa", através da legitimação de discursos opressores que naturalizam papeis sociais para homens e mulheres, o que se opõe aos preceitos do ecofeminismo que aponta para o convívio como complemento (não neutralizador de diferenças, portanto, mas considerando-se singularidades entre gêneros) e não como (modo de) exploração visando, sob olhar ecofeminista, à desestabilização das hierarquias de gênero.

O termo gênero aponta para a representação de um sistema de signos e símbolos que denotam relações de poder e hierarquia entre os sexos (SCHIENBINGER, 2001). Neste sentido, para Laurentis (1994, p. 211) "gênero representa não um indivíduo e sim uma relação, uma relação social; em outras palavras, representa um indivíduo por meio de uma classe". Dessa forma, "ideologias de gênero prescrevem características e comportamentos aceitáveis para homens e mulheres [...] a identidade de gênero denota como um homem ou

https://periodicos.unifap.br/index.php/letras

Macapá, v. 7, n. 4, 2을 semestre, 2017 
uma mulher individualmente apropria aspectos de ideologias de gênero como parte de seu senso de eu" (SCHIENBINGER, 2001, p. 46).

Sendo a primeira mulher a ingressar na Academia Brasileira de Letras, Rachel de Queiroz estabelece nesta obra uma personagem feminina protagonista do romance Dôra, Doralina, lançado em 1975, sendo Dôra uma mulher cheia de experiências dolorosamente negativas que povoam o universo feminino relacionando-o à servidão ao outro, o varão, que a sustenta.

Dessa forma, Rachel de Queiroz descreve o silêncio perpetuado através das ações do corpo feminino, provocado pela ação do sistema patriarcal, sendo este último percebido positivamente pelo sexo masculino representado pelo marido da personagem. Assim, o silêncio da mulher cerrada em seu comportamento aponta para as vestes estereotípicas relacionadas à mulher. Para refletir acerca destas questões, torna-se necessário acentuar que o ato de silenciar as muIheres torna-se artifício que atua na manutenção das forças opressoras do sexo-gênero possibilitando a (re)produção das práticas que acentuam o exílio e suspensão da voz feminina cada vez mais.

\section{A personagem ecofeminista de Dôra, Doralina}

O ecofeminismo, aqui utilizado para lançar luzes ao romance, envolve a problematização do movimento de opressão e dominação da mulher (Dôra), culturalmente associada à natureza sendo ambas (mulher e natureza) percebidas sob as lentes inferiorizadoras do outro e da monopolização operada pelo poder do homem (no caso da ficção, Laurinho, seu marido). Uma vez que a

[...] conexão entre a dominação das mulheres e a dominação da natureza é geralmente estabelecida,

https://periodicos.unifap.br/index.php/letras

Macapá, v. 7, n. 4, 20 semestre, 2017 


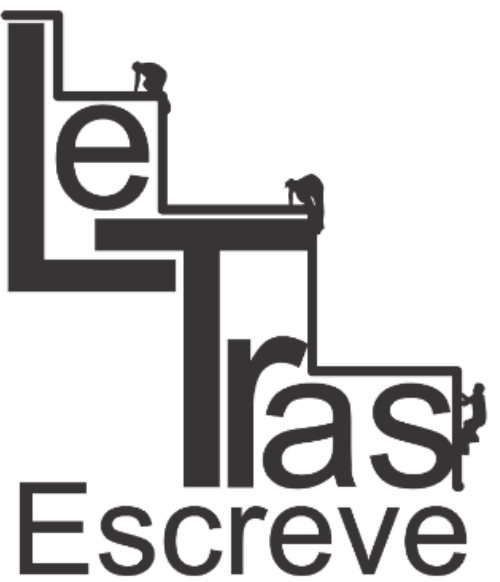

(ISSN 2238-8060)

em primeiro lugar, no nível cultural-simbólico. Registra-se a forma como a cultura patriarcal definiu as mulheres como seres 'mais próximos da natureza' ou como seres que, na cisão entre natureza e cultura, estão no lado da natureza. Isso se mostra na maneira como as mulheres foram identificadas com o corpo, a terra, o sexo, a carne em sua mortalidade, fraqueza e 'propensão ao pecado' vis-à-vis uma interpretação da masculinidade que a identifica com o espírito, a mente e o poder soberano tanto sobre as mulheres quanto sobre a natureza. (RUETHER, 1996, p. 130, ênfase no original)

Dessa forma, a personagem do romance em análise está interligada ao ecofeminismo por causa da dominação do corpo feminino através do outro, masculino, que coloniza seu espaço social e explora aquela que "nasceu para servir" e "cuidar do lar" com seus jardins, cozinha, etc. identificando-a como um ser inferior sendo esta inferiorização da mulher tomada como um parecer naturalizado enquanto verdade a partir dos efeitos do sistema patriarcal, inserido no centro da ótica que o sustenta enquanto argumento possível para observar e cercear os gêneros na sociedade. Sob a égide deste sistema, a natureza e a mulher existem para servir à humanidade e ao seu dono (sic), o homem. Sendo as mulheres associadas à natureza e a natureza sendo percebida através da dominação delas pelo outro, acentua-se o essencialismo de que um possui o outro, corroborado pelo sistema patriarcal que os enovela enquanto horizonte possível de percepção "verdadeira". Isso porque, de acordo com Silveira (2012) a imagem feminina remete ao desejo do outro. Apesar disso, algumas mulheres subjetivam-se de outras formas que não aquelas determinadas pelo discurso hegemônico identificando-se e (re) produzindo formas de subjetivação outras.

Partindo do ecofeminismo, percebemos que a personagem Dôra tem uma relação intima com a natureza e com o tempo subju-

https://periodicos.unifap.br/index.php/letras

Macapá, v. 7, n. 4, 20 semestre, 2017 
gada e dominada pelo outro, o varão que manda e diz o que deve ser feito bem como quando suas lembranças vão se impregnando de elementos da natureza quando ela recorda, por exemplo, o trabalho na fazenda e outras impressões vividas expressadas através das palavras de Dôra:

[...] embora a gente se renove como todo o mundo, tudo no mundo que não se repete jamais - pode parecer que é o mesmo mas são tudo outros, as folhas das plantas, os passarinhos, os peixes, as moscas. $A$ gente encara a natureza como uma prova parcial da eternidade - sempre há os peixes, os passarinhos, as moscas, as folhas, só as pessoas morrem e vão embora e não voltam nunca. (QUEIROZ, 2001, p. 10)

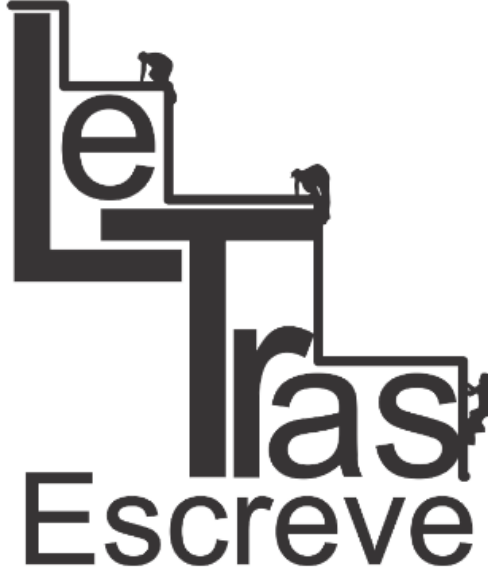

(ISSN 2238-8060)

\section{tro} tros que veem na continuidade da existência dos bichos o que vai perdurar depois que nossas vidas tiverem se extinguido. Neste contexto, Dôra aparece dotada de gestos que que a confundem na relação com o marido entre o silencio e o estranhamento, a partir do pensamento que parte do desafio de continuar vivendo com um homem que apenas a transforma em objeto, corroborado a partir das vestes de subalterna e que não a percebe a partir da diferença constituinte de alguém a ser respeitado, cuidado.

Neste contexto, cabe acentuar, portanto, o lugar da literatura como um artefato cultural que ultrapassa a ideia de representação da realidade. Não se trata de estabelecer, portanto, uma hierarquia entre literatura e mundo em que a primeira seria representante ou "tradutora" dos eventos ocorridos ou vivenciados no segundo. Dizer 
as coisas de outro modo, de um jeito único, acentuando não apenas a identificação de leitores com a ficção, mas um lugar à parte em que esse modus operandi do dizer produz efeitos em uma multiplicidade de leitores de diferentes épocas, inclusive posteriores àquela em que a obra foi escrita conforme afirmam Silveira, Dering e Lima (2016, p. 18):

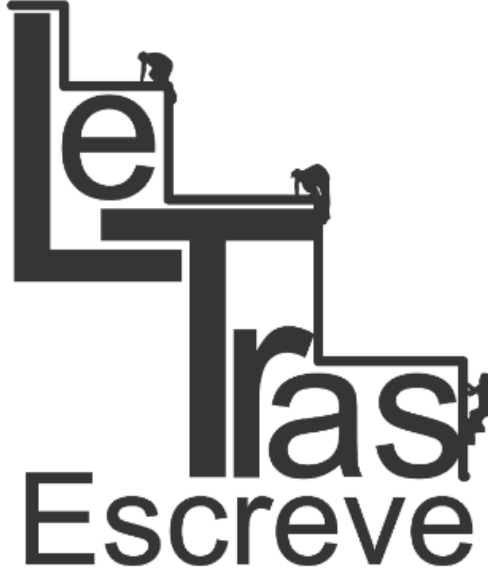

(ISSN 2238-8060)

A literatura surge como redenção do indizível, do dizer de outros modos, do encontro com lugares e situações escritas que descrevem emoções e nuances da própria vida dos leitores. Desse modo, em vez de tomar o lugar da literatura como distanciamento da realidade, nota-se com este poder que ela tem de se aproximar da realidade dos leitores ao somar as coisas ditas outro poder - o de ir além - traduzindo experiências e sentimentos não descritos, fazendo com que os leitores percebam coisas que não perceberiam de outra forma e outras tantas que estes reconhecem como suas no ato da leitura, por serem ditas dos modos que só a literatura é capaz de exprimir.

Rachel de Queiroz atingiu em sua ficção a plenitude da representação de uma personagem feminina representativa de um coletivo de gênero: forte (por suportar as ações de exploração do outro) ainda que frágil por não se ver de outro modo e não ter inculcados em si gestos de resistência em relação ao opressor, principalmente se levarmos em consideração o modo como ele a percebe, como alguém que pode servi-lo. Assim, a dinâmica patriarcal que pode ser externada através da análise do romance nutre-se a partir da exploração dessa mulher a partir de um duplo movimento: Dôra se submete aos desejos do outro e esquece-se de si. Baseado na mentalidade machista de devoção e subserviência que o masculino ecoa/dita para o feminino temos então alusão aos modos com que culturalmente são moldados e reproduzidos no seio social os lugares que "cabem" a cada

https://periodicos.unifap.br/index.php/letras

Macapá, v. 7, n. 4, 2o semestre, 2017 
um a partir da ótica que sustenta como verdade o essencialismo e a naturalizações de gêneros na sociedade que partem de dicotomizações opressoras e valorativamente positivas em relação a um (masculino) e negativas em relação a outro (feminino).

\section{0 corpo feminino de quem se fala, mas que se cala}

O corpo feminino - culturalmente revestido de signos - comporta na ficção seu peso e seu silêncio. Quando exposto e oprimido torna-se povoado por sensações e significações que externalizam regras (re)produzidas para que permaneça oculto, disfarçado, coberto. É um mostrar-se treinado pelos acontecimentos cotidianos, marcado

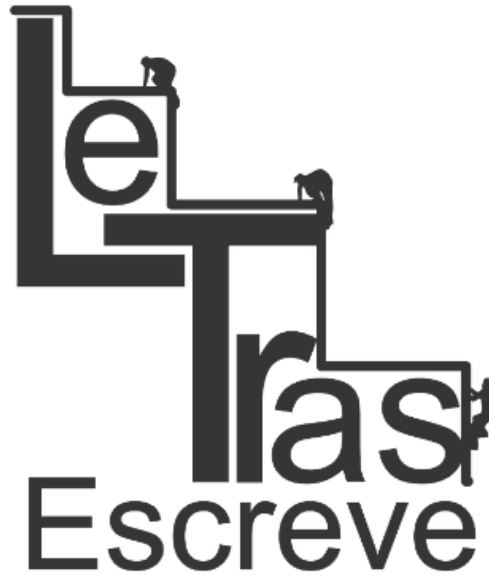

(ISSN 2238-8060) através das normas da vida cultural - de desejo, mudanças, orientação sexual -, moldado pelos discursos de moda, de masculinidade e de feminilidade que vai aos poucos apresentando lugares e comportamentos engendrados no imaginário cultural e reforçados pelo revestimento de signos cada vez mais insistentemente repetidos que visam domesticá-lo.

No romance, a elegância de estar em público constitui um dever essencialmente feminino, já que a figura do corpo belo e desejado glorifica o outro, o parceiro viril e afortunado na "amostragem" da mulher que este possui (sic). Afinal, "ser mulher é perder-se no tempo, foi a regra da minha mãe" (2000, p. 454), nas palavras de Nélida Piñon em I love my husband. Desse modo, Piñon expõe a condição do corpo feminino cuja regra é servir ao varão para que este possa "ostentar a beleza de sua(s) amante(s): um luxo que ele se pôde permitir e que Ihe glorifica a virilidade" (PERROT, 2003, p. 14).

Alguns filósofos creem que, se os homens estivessem dispostos a realizar as tarefas que foram culturalmente atribuídas e até mesmo impostas às mulheres (cuidados com a casa e procriação), o meio 


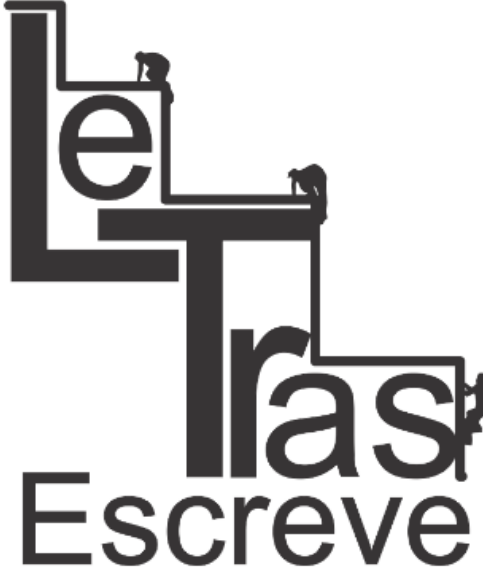

(ISSN 2238-8060) ambiente seria consideravelmente favorecido, uma vez que, segundo Mies e Shiva (apud ANGELIN, 2006) "em muitas culturas as mulheres são as responsáveis pela manutenção da biodiversidade". Esta redistribuição de tarefas causa a subversão de papeis culturalmente determinados através da história e das ações do patriarcado, resultando em maior equilíbrio entre gêneros que convivem em uma mesma comunidade, o que aponta para os fundamentos da crítica ecofeminista, cuja ecologia não se baseia apenas no que é fisicamente da natureza como elementos exteriores ao homem, mas inclui os seres humanos enquanto situado nas relações com o meio ambiente. Provoca-se assim um deslocamento significativo que aponta para o respeito à biodiversidade não apenas de flora e fauna enquanto entidades exteriores, mas ao encontro responsável com cada ser que habita no planeta em que vivemos.

No romance em análise, a personagem Dôra oferece seu corpo ao esposo Laurinho para que a ele seja fornecido o prazer sexual sem que seja considerada para ela a realização amorosa, cujo corpo feminino "valorizado" na cama serve, sob as vestes do utilitarismo alheio, para alimentar o desejo do outro. Esse corpo reduzido ao silêncio do prazer de Laurinho configura uma espécie de natureza ontológica da mulher que the proíbe excessos e incute normas que a colocam em lugares de discrição, como se esta não tivesse o direito de se manifestar sob pena de perder a elegância, conforme discutido por Michelle Perrot (2003, p. 15):

[...] a convivência ordena às mulheres da boa sociedade que sejam discretas, que dissimulem suas formas com códigos, aliás, variáveis segundo o lugar e o tempo. (...) deve mostrar comedimento nos gestos, nos olhares, na expressão das emoções, as quais não deixará transparecer senão com plena consciência. A mulher decente não deve erguer a 
voz. O riso lhe é proibido. Ela se limitará a esboçar um sorriso.

A esta altura, Cabe destacar que o silêncio relegado ao corpo opera em um lugar de censura da vida íntima da mulher e o prazer Ihe é negado através da expressão "coisa de homem" referindo-se a ambientes em que o prazer sexual estivesse presente na vida "afetiva" do casal. Afinal, "[..] as distâncias que Laurinho ia tomando de mim eu, inocente, achava que dever ser 'coisa de homem', como Xavinha dizia" (QUEIROZ, 2001, p. 45). Do mesmo modo, "sempre me disseram que a alma da mulher surgia unicamente no leito, ungido seu sexo pelo homem" (PIÑON, 2000, p. 454).

As raízes desse silêncio revestem-se do pensamento simbólico ligado historicamente a diferença dos sexos. É o estereótipo da feminilidade cuja crença mantém a tradicional posição sexual do poder do falo relacionado à posição "natural" da mulher em relação ao homem. A imagem feminina ficcional de Rachel de Queiroz e Piñon opera a construção sociocultural das virtudes do ser mulher, percebido no corpo silenciado pela descrição dos gestos de submissão que são externalizados através do corpo feminino. É nesse sentido que o ecofeminismo visa operar problematizações já que propõe a desconstrução de dominadores e apoia-se no equilíbrio entre os ciclos de vida e as relações estabelecidas entre homens e mulheres na tentativa de conservar o encontro que não neutralize diferenças horizontalizandoas sob uma ótica normalizadora de um gênero sobre o outro, além de redirecionar o olhar para o equilíbrio ecológico, uma vez que, enquanto sujeitos, dividimos o mesmo espaço da natureza.

Entretanto, Dôra comporta a apresentação de um corpo calado diante da submissão da "boa" educação, ensinada por sua mãe, em relação às atitudes e expectativas que se esperam de uma mu- 


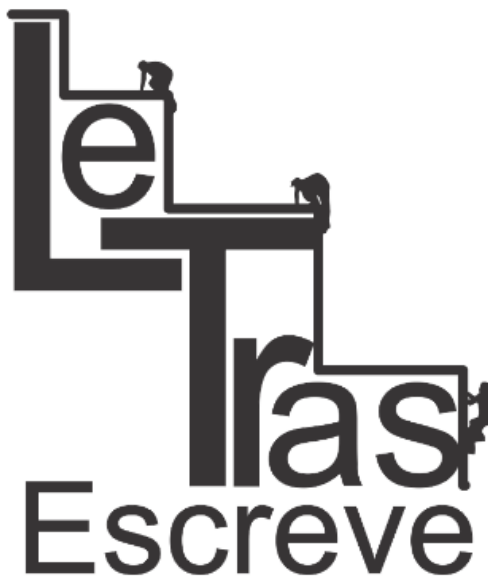

(ISSN 2238-8060)

Iher. Assim, nas palavras de Rachel de Queiroz, o marido Laurinho cobiça pelo "anjo servidor", ou seja, uma mulher "[...] pra amar, parir e morrer" (QUEIROZ, 2001, p. 45). Essas considerações vêm ao encontro das discussões de Susan Bordo (1997, p. 23), estudiosa feminista sobre os estudos do corpo, que afirma que “[...] a 'dama' do século XIX era idealizada em termos de delicadeza e encanto, passividade sexual e uma emocionalidade encantadoramente instável e caprichosa". Essa noção da feminilidade "normal" emerge no romance em questão através da relação entre corpos que Dôra tem com o marido, no sentido em que a relação de ambos revela um amor de posses, da menina moça que se casa pra não ficar pra "titia", resignando-se em ser a "dona de casa".

A partir do olhar sobre os corpos femininos submissos através da narrativa de Rachel de Queiroz, Dôra vai acentuar a situação de seu casamento: “[...] na verdade nunca foi a nossa vida uma vida igual à dos outros casais na sua casa. (...), e se poderia dizer que nós éramos mais como um casal de meninos, brincando emprestado de marido e mulher" (QUEIROZ, 2001, p. 49). Desse modo, a invisibilidade social da mulher "termina" a partir do momento que o homem - e seu esperma - a conhece (para que então ela assuma a encarnação dos códigos culturalmente produzidos pelo patriarcado para ela e só assim pode se dar sua existência "legítima" enquanto pertencente a determinado gênero). É assim o discurso de dominância e subordinação envolve os corpos femininos, seja dentro ou fora do seu âmbito particular e assim operam os meios que reprimem os desejos femininos e que objetivam as relações de poder sexista. É dessa forma que Rachel de Queiroz expõe o corpo da mulher silenciadamente marcado por construções estereotípicas de feminilidade.

https://periodicos.unifap.br/index.php/letras

Macapá, v. 7, n. 4, 2 o semestre, 2017 


\section{O pertencimento ao outro: o que quer, o que pode (ainda) o pa- triarcado?}

Sobre a obra de Rachel de Queiroz, podemos afirmar que se trata da história de um romance de narração cíclica já que, nos dizeres de Gurgel "[...] é a fábula da cobra que morde o próprio rabo" (1997, p. 42), já que a personagem Dôra vive na fazenda Soledade com Senhora, vivendo, portanto, sob a tutela de uma a mãe opressora, que mantém sempre a expressão fria e distanciada mantendo sua filha submissa aos seus modos, que servem aos interesses do modelo patriarcal. Sobre sua mãe, pode-se dizer que trata-se de uma "Senhora" que um dia pertenceu a um "Senhor", mas que reina soberana

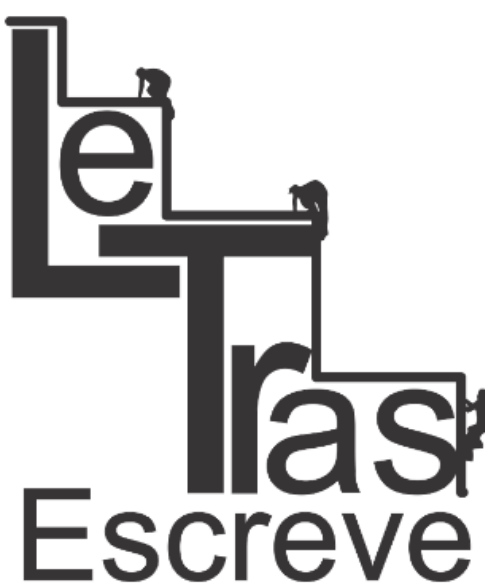

(ISSN 2238-8060) sobre um grupo de mulheres, onde um dia adentra Laurinho que se casa com Dôra e vivem ambos sob a tutela da Senhora, mãe de Dora.

Cabe então contextualizar que nas décadas de 30 e 40, as muIheres conheciam seus maridos por intermédio dos pais e casavam-se satisfazendo valorações que os mais velhos apresentavam como "virtudes" e considerassem um "bom casamento" à despeito de qualquer relutância em relação ao sistema culturalmente (re)produzido, já que, nas palavras de Beauvoir (1967, p. 165) “[...] o destino que a sociedade propõe tradicionalmente à mulher é o casamento" e o casamento de Dôra com Laurinho logra esse jogo do qual não se consegue desvencilhar:

[...] eu pensava que casamento não tem jeito, uma vez a gente casando é igual à morte, definitivo; ou não: eu pensava que casamento era como laço de sangue, como pai e filho - a gente pode brigar, detestar, mas mesmo assim está unido, ruim com ele, pior sem ele, o sangue é mais grosso que água, essas coisas. Com o nó do padre e do juiz eu teria ganho minha vitória para sempre e ele agora era meu assinado no papel. (QUEIROZ, 2001, p. 45) 
Dôra torna-se representação de mulheres que vivem sob regimes opressores em diversas partes do mundo já que o pensamento patriarcal foi sendo reproduzido por gerações como calcado em uma espécie de fala prescritiva indescartável que não poderia ser contestada pelas mulheres e as que o fizessem corriam o risco de serem deserdadas ou adjetivadas pejorativamente. Assim, através da história, a mulher passou a ser estrategicamente encarregada das tarefas do lar e para bem servir o marido, sendo qualificada como "rainha do lar" e tinha como destino um casamento sem retorno, ou seja, "pra toda a vida" ou, como elucida Piñon em seu conto, Dôra (a mulher) "[...] é a sombra do homem que todos dizem eu amar" (2000, p.451).

Com isso, a mulher como provedora desse lar envolve em sua

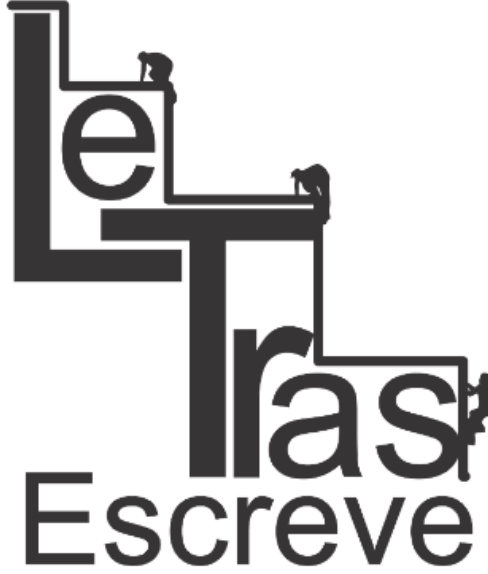

(ISSN 2238-8060)

"essência" geradora uma aproximação com a natureza, permanecendo numa posição inferiorizada hierarquicamente entre a tradição patriarcal e a natureza. Ocorrem, dessa forma, desvalorizações do feminino igualando-a com a natureza sendo que ela se aproxima da natureza é porque ambas tiveram seus direitos descartados e negligenciados aos olhos dos homens. Dessa forma, percebemos que há hierarquias (re)produzidas no interior das relações de poder que perpassam a tríade mulher-homem-natureza (sendo o homem o centro regulador a partir do qual os eixos limítrofes se estabelecem a partir dele como ponto de referência).

O casamento de Dôra ganha o clímax na traição de Laurinho a partir de um relacionamento íntimo com Senhora, agravando-se o conflito entre mãe e filha, o que é causa de grande polêmica para a sociedade da época. Senhora tenta satisfazer seu corpo traindo seu próprio ventre, rompendo assim com a filha, fruto de sua maternidade. Metaforicamente aqui podemos perceber o abandono da personagem Dora pelo marido, por quem é silenciada e alienada, já que ele 


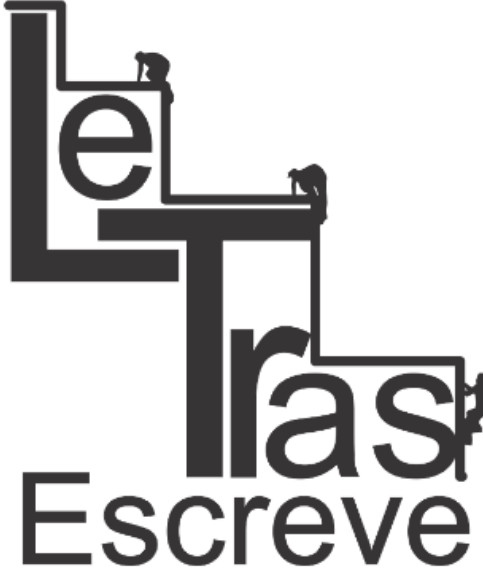

(ISSN 2238-8060) a utiliza para satisfazer-se sexualmente e para que esta seja serviçal dele e pela mãe que se torna opressora de Dôra, desencorajando-a a gestos de resistência ao reforçar através dos gestos matriarcais que imperavam a reverberação de comportamentos submissos a serem reproduzidos e também quando esta tem relações com o genro, marido de Dôra. Neste contexto, o corpo em silêncio da personagem traída torna-se reação-resposta revelada através de choro, de revolta e de mágoa: "No dia seguinte amanheci de cama. Ninguém estranhou, pensaram decerto que eram os meus achaques. Bílis! [...] Dois dias fiquei assim, sem me levantar nem comer, tomando chá na cama e sem responder a ninguém" (QUEIROZ, 2001, p. 54).

Em relação ao casamento de ambos, pode-se afirmar que não há reciprocidade, pois socialmente o homem é visto como um ser completo e autônomo, enquanto a mulher um ser incompleto e frágil e até hoje o discurso sexista reforça a imagem de que as mulheres ainda não alcançaram a igualdade com o "cérebro" masculino (como se as mulheres necessitassem tomar o masculino como ponto de partida para neutralização das diferenças, ao invés de perceberem-se como sujeitos singulares e únicos dotadas de diferença que não quer ser incorporada sob os discursos do outro). Assim, Funck (2011, p. 69) aponta que:

[...] o problema, portanto, não é efetivamente a diferença em si, a diferença entre mulheres e homens. O problema é a diferença vista como sendo da mulher em relação ao homem. É o modo pelo qual a diferença é apreendida e tratada como imperativa e essencial. É a forma pela qual ela afeta nossos modelos de conhecimento e relacionamento, com vantagens para alguns e desvantagens para outros. E é por essa razão que temos necessidade de entender o discurso, a linguagem em uso, não como um sistema transparente de significado do mundo, mas como o próprio instrumento de sua construção, 
pois o processo pelos qual adquirimos conhecimento é discursivo.

Depois da morte misteriosa de Laurinho, Dôra muda-se para Fortaleza deixando a casa sob os cuidados de Senhora, representação do sistema patriarcal, regido pela valorização da diferença hierarquicamente defendida entre os sexos. Desse modo, a personagem parte para desbravar sua liberdade, rompendo com um passado estreito e em busca de novas perspectivas. Rachel de Queiroz finaliza o Livro de Senhora com as afirmações "[...] tirei o luto para a viagem. Se pudesse tirava a pele, arrancava os cabelos, saía em carne viva" (QUEIROZ, 2001, p. 63). Assim, a narradora anuncia a etapa existencial do rito de passagem da personagem assemelhando-se a liberdade possibilitada pela morte do marido de Dora com tom de ironia de Piñon em "ah, sim, eu amo meu marido" (PINÑON, 2000, p. 456).

A liberdade de escolha da mulher por diversas vezes foi abortada por causa de práticas e naturalizações acerca dos gêneros cada vez mais voltadas para a depreciação de ações de recusa às regras (re)produzidas social e culturalmente. O casamento, visto sob o prisma da história de Dôra, torna-se reforçador de costumes historicamente situados em regimes patriarcais que apontam para a natureza ontológica "essencialista" do que é "ser esposa", tomando a mulher como referência ao marido, o que ajudou a produzir e reforçar o silenciamento da personagem. Dôra casa-se com Laurinho para viver "harmonicamente" dentro de um lar, em que vê no homem um intermediário entre sua individualidade de ser mulher e o universo e ele se vestirá de um valor humano/social natural atrelado aos interesses do patriarcado, situação agravada pelo fato de que ela não conhece outros modelos de união que não o casamento nem realidades de outras mulheres da época que não estivessem assentadas co- 


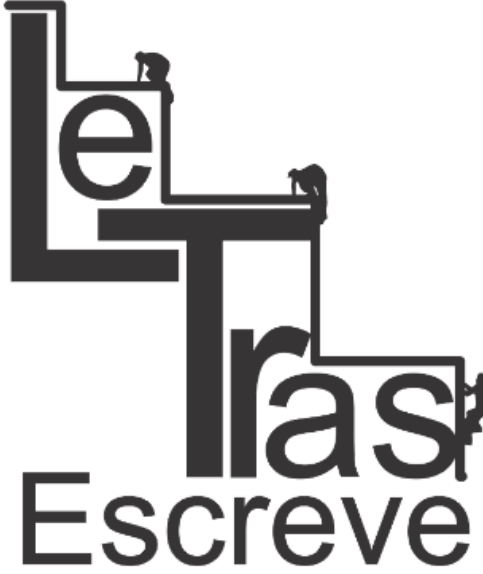

(ISSN 2238-8060)

letivamente sob o objetivo de casar-se.

Através do contexto literário, o ecofeminismo possibilita tecer reflexões sobre o texto no sentido de problematizar as ideologias culturalmente dominantes e naturalizadas através dos gestos e prescrições do outro operando sobre os corpos com vigilância constante (FOUCAULT, 2003). Dôra para Laurinho é um ser tido como inferior, assim como, na esteira do mesmo argumento, a natureza é construída ideologicamente para humanidade. Para Isabel Brandão (2003, p. 465) pode-se então refletir sobre os gêneros sociais enquanto parte de uma ecologia e, assim, "[...] a natureza torna-se, pois, um campo de resistência e de luta para as mulheres, num contexto mais específico, e num mais amplo, de resistência contra a opressão e exploração generalizada do planeta".

Laurinho, o marido, passa a ser justificativa de Dôra para responder às provocações da mãe dela, provando que ela poderia ter um homem que a desejasse como esposa. No entanto, a máscara que ocultava a natureza opressora do casamento não havia sido apresentada antes dela unir-se ao marido, pois nunca atentou para as obrigações de casada, mas admitia que, no início, sentiu-se envolvida pela existência de um "homem da casa" em detrimento às fronteiras estreitas da fazenda e sua vida limitada às regras de Senhora. Assim, com pouca vivência do mundo exterior à casa da mãe, Dôra não estabelecia comparações sobre aquela figura de homem que tinha através da experiência com o marido e outros homens a ponto de chegar a considerá-lo como modelo ideal de marido (por estar inserida em uma sociedade historicamente constituída por categorizações que apresentavam-no como tal a partir dos estereótipos vigentes e estar imersa em uma educação que a havia ensinado isso). Vale destacar, neste contexto que "[...] as formas de comportamento escolhidas por 


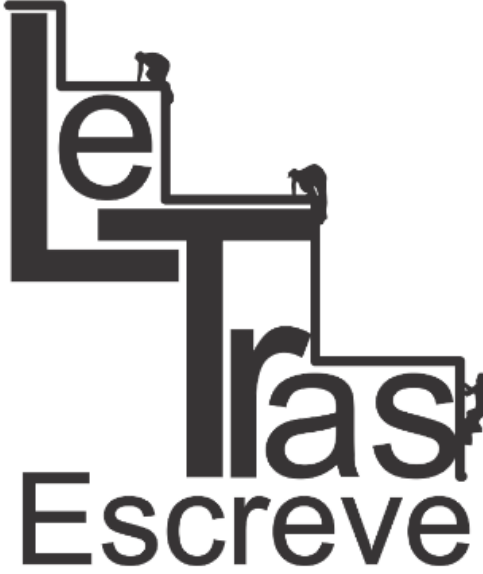

(ISSN 2238-8060) nossa sociedade e transmitidas aos jovens por meio da educação são o reflexo da ideologia que a domina, têm muito pouco de universais e de inerentes ao ser humano e são, portanto, modificáveis" (MORENO, 1999, p. 34)

No bojo das discussões que apregoam possibilidades de resistência às naturalizações de gênero, o ecofeminismo dimensiona as reflexões para a necessidade de se conhecer a natureza como uma unidade cooperativa que é a vida, onde os humanos e os não humanos vivam em comunidade a partir do respeito aos espaços em que ambos coexistem. Dessa forma, a personagem do romance de Rachel de Queiroz emerge enquanto representação dos efeitos do modelo civilizatório (sic) representado pelo patriarcado bem como pode apontar para a inserção em reflexões acerca da relação entre os seres humanos entre si e com a natureza e o meio social, cuja teoria feminista perpassa entre o feminismo e a ecologia em algumas partes do romance como aquela que destacamos anteriormente acerca de suas lembranças e reflexões sobre a finitude. Cabe então ampliar o escopo de considerações entre humanos e a natureza trazendo à tona que a opressão e a dominação de Dôra se assemelham àquelas operada sobre a natureza, já que historicamente ambas são percebidas como sujeitos destituídos de voz no interior do sistema de imposições hierarquizadoras. Dessa forma, o ecofeminismo tratado no presente trabalho remete a dominação do gênero, do outro (o ser mulher, Dôra) e sua relação com aquele que é apresentado, através de naturalizações, portanto, como seu oposto e eixo regulador das generificação impostas social e culturalmente a ela.

\section{No final das andanças retorna-se ao lugar de onde se partiu...}

Rachel de Queiroz trabalha ficcionalmente a partir de temas 


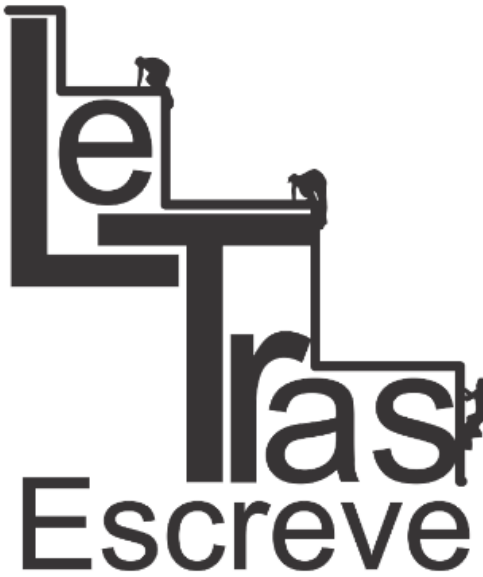

(ISSN 2238-8060) continuamente reverberadores dos efeitos das condições sociais estabelecidas entre gêneros em nossa sociedade. Dessa forma, possibilita reflexões acerca dos casamentos forçados, dos infanticídios sexuais, da prostituição, da violência doméstica. Dessa forma, ela aborda o silêncio do corpo feminino apresentado como "natural", regido por sistema culturalmente patriarcal em que a mulher é vista como um ser submisso, destinada a dar prazer e para a procriação.

A voz e o domínio masculino que governam e impõem generificações confirmam a crítica do pensamento feminista da posição universal de diferença sexual hierarquizada entre homens e mulheres que enovela-os em posições e lugares essencializadores na sociedade. O discurso sexista encontra-se, dessa forma, limitado à cultura do patriarcado, aos modelos historicamente reproduzidos a partir da estereotipação da mulher, enquanto fêmea submissa às ordens do macho. Assim, a análise da primeira parte do romance, intitulada $O$ Livro de Senhora, se interliga ao questionamento do ecofeminismo fazendo com que a literatura seja ferramenta de problematização acerca dos modos como são muitas vezes objetivadas as mulheres na sociedade.

Desse modo, em Dôra, Doralina os ecos femininos são monitorados (e cerceados) pelo poder do masculino. Laurinho (o homem) dentro do espaço privado (a casa) destina suas fantasias secretas, seus desejos acesos pela submissão feminina (da mulher/da natureza). Desse modo, a narrativa sugere que o ser inferior-mulher é moldado apenas para obedecer aos desejos de quem estabelece as ordens de comportamento. Assim, o presente trabalho visa destacar que a dominação e a opressão sofridas pelas mulheres estão na base dos efeitos produzidos pela exploração da natureza e das minorias. Cabe então destacar neste contexto que tanto as mulheres quanto o

https://periodicos.unifap.br/index.php/letras

Macapá, v. 7, n. 4, 20 semestre, 2017 


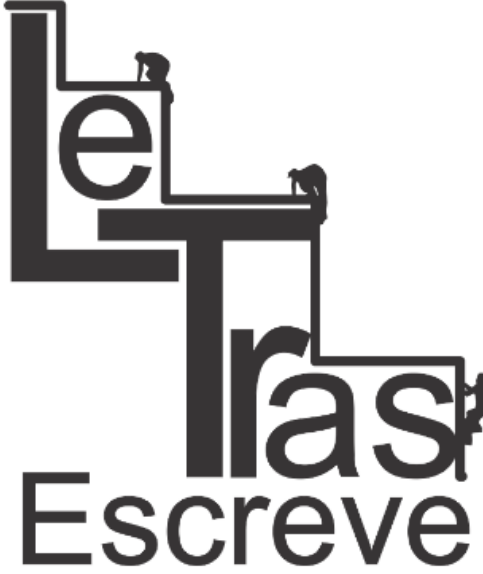

(ISSN 2238-8060) meio ambiente são tratados pelo sistema do patriarcado como "supérfluo", "imprestável", "coisa inútil", servindo apenas para satisfação ou até mesmo objeto, ou seja, subordinados ao seu poder.

Contudo, cabem as palavras de Dôra após a morte do marido enquanto marcas de rupturas possíveis que possibilitam olhares que rompem com a dinâmica do patriarcado revelando posicionamentos adversos das lógicas dominadoras e opressivas que cercam as mulheres: “- Meus pêsames" (QUEIROZ, 2001, p. 60). Cabe então problematizar a existência dos corpos femininos para que estes possam se libertar das amarras ideológicas que os circundam, classificam, categorizam, trazendo o horizonte de outras alteridades possíveis para o feminino. Por isso, o presente trabalho buscou apresentar-se sob as vestes das implicações do ecofeminismo: para que fosse externado através da ficção utilizada para análise das questões que aqui foram apresentadas, um ser (eco)feminino apresentado a partir da metonímia dos efeitos da dominação dos corpos femininos situando estes corpos em relação à natureza quando esta também é silenciada, explorada, abandonada e relegada aos porões do silêncio opressor das naturalizações que engendram comportamentos e produzem efeitos de dominação.

Finalmente, cabe aqui afirmar que a mulher, associada à natureza ou não, pode ser percebida a partir da identificação com ações de resistência ao domínio que incide sobre os gêneros e não apenas através do "papel" procriador, maternal, desejado, submisso, silenciado frente aos padrões que reforçam a manutenção de seu estado de dominação. É preciso re-tecer o mundo cuidando e respeitando as diferenças sem tomar a diferença que não quer ser incorporada a partir de um eixo regulador de identidades que neutralize um dos polos em relação ao outro, seja do mesmo ou de gêneros diferentes. 
Houve alguns avanços na sociedade contemporânea, sobretudo o que aponta para a revolução das mulheres em diversos campos, o que possibilita direcionar o pensamento a partir de reflexões subversivas que encaminhem para olhares críticos em relação a cada época a fim de não cessar as desconfianças em relação às naturalizações que engessam, produzem subjetividades e silenciam sujeitos, sem deixar de lado o olhar para as relações entre os seres humanos entre si e com o ambiente em que vivem. Isso porque

[...] o papel da mulher ao longo da história da humanidade, mesmo passado por uma dominação patriarcal machista, vem libertando-se a cada dia, e conquistando seu espaço na sociedade, mudando conceitos, concepções, culturas e dando ao ser humano, sua essência feminina, para trazer luz aos paradigmas enfrentados na idade contemporâneo, principalmente frente de questões ligadas a problemática ambiental emergente e sua contribuição primordial na revitalização de uma sociedade sustentável, com visas a um futuro equilibrado e em consonância com o meio ambiente. (CÓRDULA; NASCIMENTO, 2012, p. 146)

\section{Referências}

ANGELIN, Rosângela. Gênero e meio ambiente: a atualidade do ecofeminismo. Revista Espaço Acadêmico, v 58, no 5, 2006.

BEAUVOIR, Simone de. O segundo sexo. v. II. 2. ed. Trad. de Sérgio Milliet. São Paulo: Difusão Europeia do Livro, 1967.

BORDO, Susan R. O corpo e a reprodução da feminidade: uma apropriação feminista de Foucault. In: BORDO, Susan R.; JAGGAR, Alison M. Gênero, corpo, conhecimento. Tradução de Brítta Lemos de Freitas. Rio de Janeiro: Record; Rosa dos Tempos, 1997.

BRANDÃO, Izabel. Ecofeminismo e literatura: novas fronteiras críticas. In: BRANDÃO, Izabel; MUZART, Zahidé L. (org.). Refazendo nós: en- 


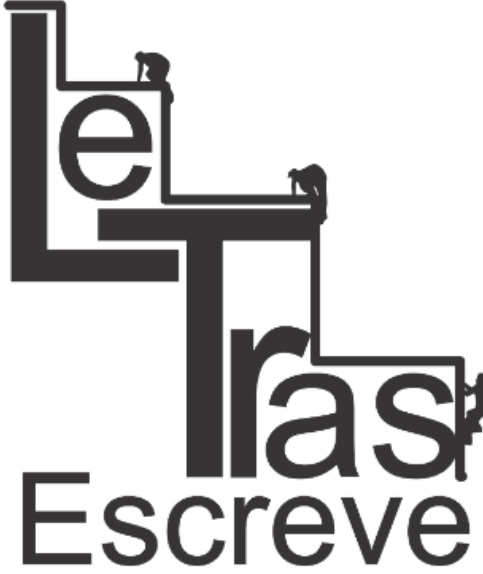

(ISSN 2238-8060)

saios sobre mulher e literatura. Florianópolis: Mulheres, 2003.

CÓRDULA, Eduardo Beltrão de Lucena; NASCIMENTO, Glória Cristina Cornélio do. Ecofeminismo na contemporaneidade. Revista meio ambiente e sustentabilidade. vol. 2, n. 1. Julho-dezembro de 2012, p. 143-148.

FOUCAULT, Michel. Vigiar e punir. Trad. Raquel Ramalhete. Petrópolis: Vozes, 2003.

FUNCK, Susana Bornéo. O que é uma mulher? In: CERRADOS: Revista do Programa de Pós-graduação em Literatura (Palavra e poder: representações na literatura de autoria feminina). Vol. 20 no 31, Brasília: Universidade de Brasília, Departamento de Teoria Literária e Literaturas, 2011, p. 63-74.

GARCIA, L. G. Ecofeminismo - a teoria das conexões. Material Didático da Disciplina de Sociedade e Natureza, Mestrado-PRODEMA/UFPB, João Pessoa: UFPB, 2012.

GURGEL, Ítalo. Uma leitura íntima de Dôra, Doralina: a lição dos manuscritos. Fortaleza: Casa José de Alencar, 1997.

LAURENTIS, Tereza. A tecnologia do gênero. In: HOLLANDA. Heloisa Buarque de. Tendências e impasses: o feminismo como crítica da cultura. Rio de Janeiro: Rocco, 1994.

PERROT, Michelle. Os silêncios do corpo da mulher. In: MATOS, Izilda $S$ de; SOIHET, Rachel. $O$ corpo feminino em debate. São Paulo: Editora da UNESP, 2003, p. 13-27.

PIÑON, Nélida. I love my husband. In: MARICONI, Ítalo. Os cem meIhores contos brasileiros do século. Rio de Janeiro: Objetiva, 2000. PINTO, Francisca Lailsa Ribeiro; SILVEIRA, Éderson Luís. A mulher entre (in)visibilidades e corpos adormecidos: percebendo o gênero nas tessituras do silêncio. Revista Espaço Acadêmico (UEM), v. 14, p. 95106, 2014.

https://periodicos.unifap.br/index.php/letras

Macapá, v. 7, n. 4, 2을 semestre, 2017 
QUEIROZ, Rachel de. Dôra, Doralina. 9. ed. São Paulo: Siciliano, 2001.

RUETHER, Rosemary R. Ecofeminismo: mulheres do primeiro e do terceiro mundo. Revista Estudos Teológicos, v 36, no 2, 2006, p. 129139.

SALEH, Ariel. Ecosocialismo - ecofeminismo. Nueva Sociedad. n. 122, p. 230-233, Noviembre-diciembre de 1992.

SHIENBINGER, Londa. O feminismo mudou a ciência? Trad. Raul Fiker. Bauru, SP: Editora EDUSC, 2001.

SILVEIRA, Éderson Luís. Corpos silenciados em busca de identidade: Espelhos que refletem a falta. PRACS: Revista Eletrônica de Humanidades do Curso de Ciências Sociais da UNIFAP, v. 5, p. 29-40, 2012.

SILVEIRA, Éderson Luís; DERING, Renato; LIMA, Omar Silva. Sobre insistências e reminiscências do eco: a literatura sob o viés dos vagalumes que ainda resistem. Imagens da Educação, v. 06, p. 13-23, 2016.

Recebido em 21/02/2017

Aceito em 20/07/2017 